\title{
Sympathetic Cardiovascular Function Status of Chronic Obstructive Pulmonary Disease (COPD)
}

\author{
Baksh $\mathrm{S}^{1^{*}}$, Akhter $\mathrm{S}^{2}$, Ali $\mathrm{OI}^{3}$, Munna $\mathrm{MK}^{3}$, Rownak $\mathrm{N}^{4}$, Khan $\mathrm{SM}^{5}$ \\ ${ }^{1}$ Department of Physiology, Cox's Bazar Medical College, Cox's Bazar, ${ }^{2}$ Department of Physiology, \\ Chittagong Medical College, Chittagong, Bangladesh; ${ }^{3}$ Department of Physiology, Rajshahi Medical \\ College, Rajshahi, Bangladesh; ${ }^{4}$ Department of Physiology, USTC, Chittagong, Bangladesh; \\ ${ }^{5}$ Department of Urology. Chittagong Medical College, Chittagong, Bangladesh
}

\begin{abstract}
Background: Chronic obstructive pulmonary disease (COPD) is a chronic progressive obstructive airway disease which is often associated with cardiovascular diseases. Sympathetic dysfunction may complicate the cardiovascular diseases which may in turn increase the morbidity and mortality in COPD patients.

Objective: Aim of this study was to evaluate sympathetic cardiovascular function status of COPD patients to reduce the cardiovascular complication in those patients.

Methods: This comparative cross-sectional study was carried out at the department of Physiology and department of Medicine, Rajshahi Medical College, Rajshahi from July 2013 to June 2014.

Results: A total number of 80 subjects aged 40-55 years were selected, among which 40 were clinically diagnosed COPD patients (case) and 40 were age, sex and BMI matched apparently healthy persons for comparison (control group). To observe sympathetic cardiovascular function status resting pulse rate, resting systolic BP, resting diastolic BP, decline of systolic BP in response to standing from lying position (orthostatic test) and rise of diastolic BP in response to sustained hand grip for 5 minutes (isometric exercise test) were measured. For statistical analysis Independent sample t-test, and Pearson's correlation coefficient test were performed. In this study resting pulse rate, systolic BP, diastolic BP and rise of diastolic blood pressure in isometric exercise test were significantly increased in COPD than in healthy control group. On the other hand, decline of systolic blood pressure in orthostatic test was significantly decreased in COPD than in control group.

Conclusion: This study concludes that sympathetic cardiovascular function is overactive in COPD and sympathetic over activity correlates with severity of the disease.
\end{abstract}

Keywords: Sympathetic dysfunction, COPD, Isometric exercise test, Orthostatic test

\section{Introduction}

Chronic Obstructive Pulmonary Disease (COPD), a common preventable and treatable disease is characterized by persistent airflow limitation that is usually progressive and associated with an enhanced chronic inflammatory response in the airways and the lungs to noxious particles or gases. ${ }^{1}$ It is a major cause of morbidity and mortality throughout the world. ${ }^{\mathbf{1}}$ Current estimates suggest that 80 million people worldwide suffer from moderate to severe form of this disease. In 2005, COPD contribute to more than 3 million deaths ( $5 \%$ of deaths globally), but by 2020 it is forecast to represent the third most important cause of death world-wide. The anticipated rise in morbidity and mortality from COPD will be greatest in Asian and African countries as a result of their increasing tobacco consumption. ${ }^{2}$

Autonomic nervous system is the part of nervous system that is responsible for homeostasis. ${ }^{3}$ It controls most visceral functions of the body such as

Correspondence: Dr. Sohel Baksh, Department of physiology, Cox's Bazar Medical College, Cox's Bazar, Chottagram, Bangladesh;

e-mail: sohel.baksh@gmail.com; ORCID: 0000-0001-9475-2729 heart rate, arterial pressure, gastrointestinal motility and secretion, urinary bladder emptying, sweating, body temperature etc. Autonomic nervous system has two major subdivisions. One is sympathetic nervous system and another is parasympathetic nervous system. ${ }^{4}$

COPD may alter autonomic nerve function and may produce sympatho-excitation. ${ }^{5,6}$ There is increasing evidence that the edema which develops late in the course of disease in patient with COPD may not be entirely due to right ventricular failure. Sympathetic nerve dysfunction, which is relatively common in patient with severe COPD may also contribute to the salt and water retention in thesepatients. ${ }^{7}$

In patients with mild to moderate COPD, the leading cause of morbidity and mortality is cardiovascular disease. COPD patients have two to three times the risk of hospitalization for cardiovascular diseases. ${ }^{8}$ TORCH (Towards a Revolution in COPD Health) study shows that $27 \%$ of mortality of COPD patients occurs due to cardiovascular diseases. ${ }^{9}$ 
To diagnose autonomic nerve dysfunction five simple non-invasive cardiovascular reflex tests are done that have been applied successfully in many studies. ${ }^{10,11}$

Among them two standard tests including isometric exercise test (BP response to sustained handgrip) and orthostatic test (BP response to standing) are usually done to assess cardiovascular sympathetic nerve function. ${ }^{12,13}$ These tests have now become the gold standard by which sympathetic nervous system function is assessed. ${ }^{13}$

Several studies on sympathetic nerve function status have done in various diseases and conditions in Bangladesh. But so far we know, no study was done on sympathetic cardiovascular functional status in chronic obstrucive pulmonary disease patients inthis country.

Therefore, the present study was designed to observe sympathetic cardiovascular functional status in patients with COPD. This study will help the clinician to reduce cardiovascular complications in COPD patients.

\section{Materials and Methods}

This analytic type of comparative cross sectional study was done in Department of Physiology and Medicine, Rajshahi Medical College, Rajshahi during July, 2013 to June, 2014. For this, a total number of 80 subjects with age range 40 to 55 years of whom 40 stable COPD patients and 40 apparently healthy subjects were included. Stable chronic obstructive pulmonary disease (COPD) patients were collected from medicine ward and outpatient department of Rajshahi Medical College Hospital, Rajshahi. Age and sex matched healthy subjects were collected by personal contact.

All the study subjects were divided into two groups. GroupA consisted of 40 apparently healthy age and BMI matched male subjects. Group-B consisted of 40 clinically diagnosed male stable COPD patients.

Patients with acute exacerbation of COPD, diabetes mellitus, ischemic heart disease, Chronic kidney disease, rheumatoid arthritis, hyperthyroidism, other pulmonary diseases like bronchial asthma, bronchiectasis and pulmonary fibrosis, any other chronic systemic diseases were excluded from this study. The protocol was approved by the Institutional Review Board and Ethical Review Committee of Rajshahi Medical College.

After selection of subject the aim, objectives, nature, purpose and potential risk of all procedures used for the study were explained in detail to each subject. They were encouraged for voluntary participation and allowed to withdraw themselves from the study even after participation whenever they liked. Their informed written consent was taken in a prescribed form.

The subjects were interviewed and detailed history regarding personal history, drug history, family history and past medical history were taken. Height and weight of the subjects were measured and BMI was calculated. Then thorough physical examinations were done and all the information's were recorded in a prefixed questionnaire.

$400 \mathrm{mcg} \beta_{2}$-agonist (Salbutamol inhaler) was inhaled by subject (in case of COPD patients). Subject was asked to take rest for $10-15$ minutes. Spirometric variables like $\mathrm{FVC}, \mathrm{FEV}_{1}, \mathrm{FEV}_{1} / \mathrm{FVC}$ ratio and $\mathrm{FEV}_{1}$ (\% of predicted) were measured for confirming the diagnosis. Then the subject was kept in complete bed rest in supine position for 15 minutes in a cool and calm environment. During this period subject was advised not to talk, eat or drink and also not to perform physical or any mental activity, even sleep. Then pulse rate of the subject was counted. Blood pressure was measured by sphygmomanometer. Two sympathetic cardiovascular reflex tests (orthostatic test and isometric exercise test) were also done by using sphygmomanometer.

Orthostatic test (blood pressure response of standing after lying):The subject was asked to lie on bed. After 15 minutes rest, his blood pressure was measured by the sphygmomanometer. Then he was asked to stand up as quickly as possible with pressure cuff tied around the arm. Again his blood pressure was measured. The differences in systolic blood pressure between lying and 1 minute after standing was calculated. Fall of systolic BP 10 or below was taken as normal, 11-29 as borderline and 30 or more as abnormal. ${ }^{12-14}$

Isometric exercise test (blood pressure response to a sustained hand grip): The subject was asked to sit quietly and his blood pressure was measured. Then he was asked to grip the inflated cuff of a sphygmomanometer at $30 \%$ of the maximum voluntary contraction for maximum 5 minutes and then again blood pressure was measured just before the release of handgrip. Rise of diastolic blood pressure (DBP) 16 or greater was regarded as normal,11-15 as borderline and 10 or below as abnormal. ${ }^{12-14}$

Structured questionnaire were used to record general information; lung function test results (related to COPD diagnosis) and sympathetic cardiovascular function test findings were recorded in data sheet.

Analysis of the data was done by using SPSS software program. All the variables were expressed as mean $\pm \mathrm{SD}$ (standard deviation). For statistical analysis Independent sample ' $\mathrm{t}$ ' test was done to compare between the groups and Pearson's correlation 
coefficient test was done to observe the relationship of the study variables with $\mathrm{FEV}_{1} . p$ value $<0.05$ was accepted as level of significance.

\section{Results}

Mean $( \pm$ SD) age and BMI of study and control group were not statistically significant $(p>0.05) . \mathrm{FVC}, \mathrm{FEV}_{1}$ and $\mathrm{FEV}_{1} \%$ were significantly $(p<0.001)$ lower in group B than group A (table I).

Resting pulse rate, systolic BP, diastolic BP and rise of diastolic blood pressure in isometric exercise test were significantly $(p<0.001)$ increased in COPD than in healthy control group. On the other hand, decline of systolic blood pressure in orthostatic test was significantly $(p<0.001)$ decreased in COPD than in control group (table II).

Table I: Age, BMI, FVC, FEV, and $\mathrm{FEV}_{1} / \mathrm{FVC}$ ratio in two groups $(\mathrm{n}=80)$.

\begin{tabular}{lccc}
\hline Parameters & $\begin{array}{c}\text { Group A } \\
(\mathbf{n}=\mathbf{4 0})\end{array}$ & $\begin{array}{c}\text { Group B } \\
(\mathbf{n}=\mathbf{4 0})\end{array}$ & $\boldsymbol{P}$ value \\
\hline Age $($ years $)$ & $47.17 \pm 2.10$ & $47.62 \pm 3.17$ & $>0.05^{\text {ns }}$ \\
BMI $\left(\mathrm{kg} / \mathrm{m}^{2}\right)$ & $25.23 \pm 2.51$ & $25.30 \pm 2.20$ & $>0.05^{\text {ns }}$ \\
FVC (litre) & $3.21 \pm 0.31$ & $2.40 \pm 0.55$ & $<0.001 * * *$ \\
FEV $_{1}$ (litre) & $2.75 \pm 0.19$ & $1.50 \pm 0.46$ & $<0.001^{* * *}$ \\
FEV1\% & $97.77 \pm 6.55$ & $55.93 \pm 17.20$ & $<0.001^{* * *}$ \\
predicted & & & \\
FEV $1 /$ FVC $(\%)$ & $86.18 \pm 6.39$ & $61.89 \pm 7.35$ & $<0.001^{* * *}$ \\
\hline
\end{tabular}

Values are expressed as mean \pm SD. Statistical analysis was done by independent sample $t$ test.

Group A: Control

Group B: COPD patients

$*=$ Significant at $<0.05$ level $* *=$ Significant at $<0.01$ level

$* * *=$ Significant at $<0.001$ level

ns=not significant at $>0.05$

Table II: Sympathetic nerve function parameters in two groups $(\mathrm{n}=80)$

\begin{tabular}{lccc}
\hline \multicolumn{1}{c}{ Parameters } & $\begin{array}{c}\text { Group A } \\
(\mathbf{n}=\mathbf{4 0})\end{array}$ & $\begin{array}{c}\text { Group B } \\
(\mathbf{n}=\mathbf{4 0})\end{array}$ & $\boldsymbol{p}$ value \\
\hline $\begin{array}{l}\text { Resting pulse } \\
\text { rate (beats/min) }\end{array}$ & $72.60 \pm 4.80$ & $83.77 \pm 8.11$ & $<0.001^{\star * \star}$ \\
$\begin{array}{l}\text { Resting SBP } \\
\text { (mm of Hg) }\end{array}$ & $114.30 \pm 6.88$ & $125.67 \pm 8.88$ & $<0.001^{\star * \star}$ \\
$\begin{array}{l}\text { Resting DBP } \\
\text { (mm of Hg) }\end{array}$ & $70.60 \pm 7.28$ & $80.27 \pm 7.86$ & $<0.001^{* \star *}$ \\
$\begin{array}{l}\text { Fall of SBP in } \\
\text { orthostatic test } \\
\text { (mm of Hg) }\end{array}$ & $10.40 \pm 12.83$ & $4.05 \pm 2.31$ & $<0.01^{\star *}$ \\
$\begin{array}{l}\text { Rise of DBP in } \\
\text { isometric } \\
\text { exerise test } \\
\text { (mm of Hg) }\end{array}$ & $16.20 \pm 0.76$ & $18.40 \pm 1.66$ & \\
\hline
\end{tabular}

Values are expressed as mean \pm SD. Statistical analysis was done by independent sample $t$ test.

Group A: Control

Group B: COPD patients

$* *=$ Significant at $<0.01$ level $* * *=$ Significant at $<0.001$ level
Resting pulse rate, resting SBP, resting DBP and rise of DBP in isometric exercise test were negatively correlated with percentage of predicted value of $\mathrm{FEV}_{1}$ in COPD patients. These relationships were statistically significant (table III, figure 1,3).

Table III: Relationship of the different study variables with percentages of predicted value of $\mathrm{FEV}_{1}$ in study group $(\mathrm{n}=40)$

\begin{tabular}{lcc}
\hline Parameter & r value & $p$ value \\
\hline Resting pulse rate (bpm) & -0.894 & $0.001 * * *$ \\
Resting SBP (mm of Hg) & -0.728 & $0.001 * * *$ \\
Resting DBP (mm of Hg) & -0.800 & $0.001 * * *$ \\
$\begin{array}{l}\text { Decline of SBP in } \\
\text { orthostatic test (mm of Hg) }\end{array}$ & 0.925 & $0.001 * * *$ \\
$\begin{array}{l}\text { Rise of DBP in isometric } \\
\text { exercise (mm of Hg) }\end{array}$ & -0.877 & $0.001 * * *$ \\
\hline
\end{tabular}

$* * *=$ Statistically highly significant

Pearson Correlation-coefficient test was done to see relationship of different study variables with percentage of predicted value of $\mathrm{FEV}_{1}$.

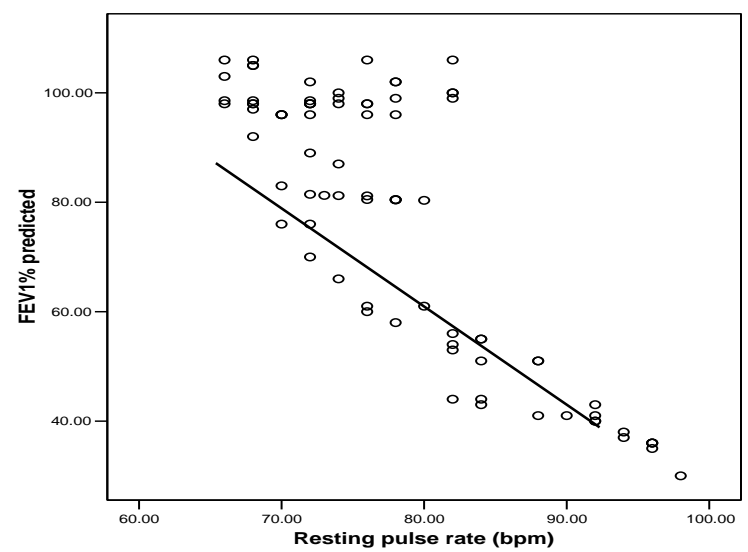

Figure 1(a): Correlation of resting pulse rate with percentage of predicted value of $\mathrm{FEV}_{1}$ in study group $(\mathrm{n}=40)$

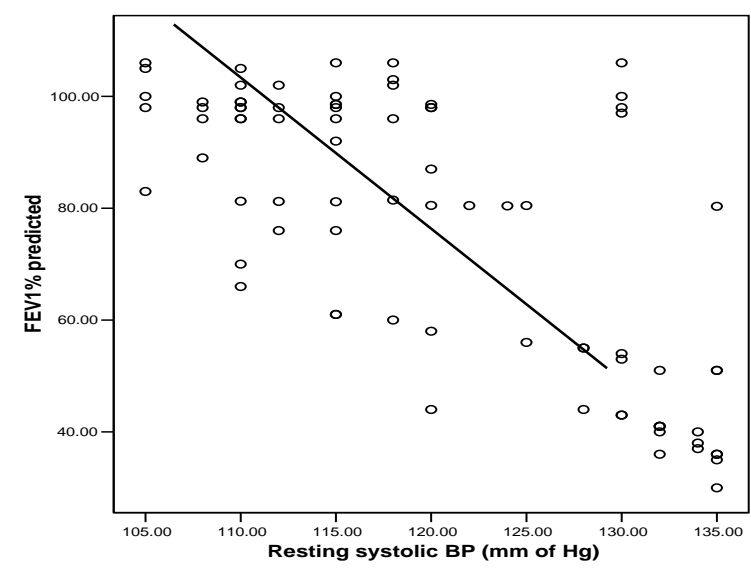

Figure 1 (b): Correlation of resting systolic BP with percentage of predicted value of $\mathrm{FEV}_{1}$ in study group $(\mathrm{n}=40)$ 


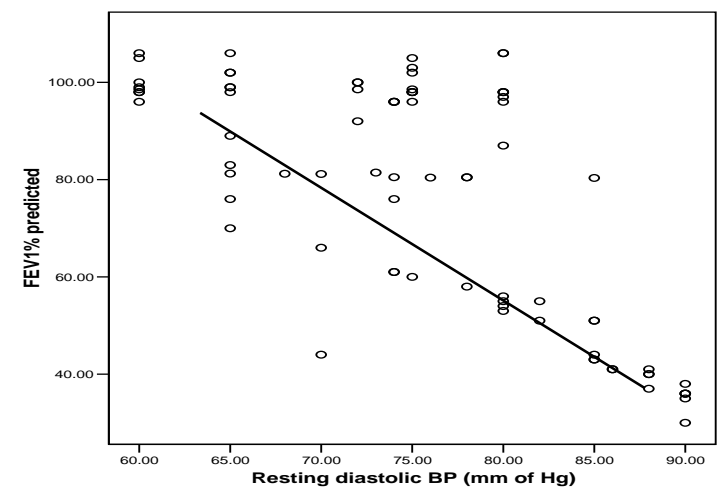

Figure 1(c): Correlation of resting diastolic BP with percentage of predicted value of $\mathrm{FEV}_{1}$ in study group $(\mathrm{n}=40)$

Decline of SBP in orthostatic test was positively correlated with percentage of predicted value of $\mathrm{FEV}_{1}$ in COPD patients. This relationship was also statistically significant (figure 2).

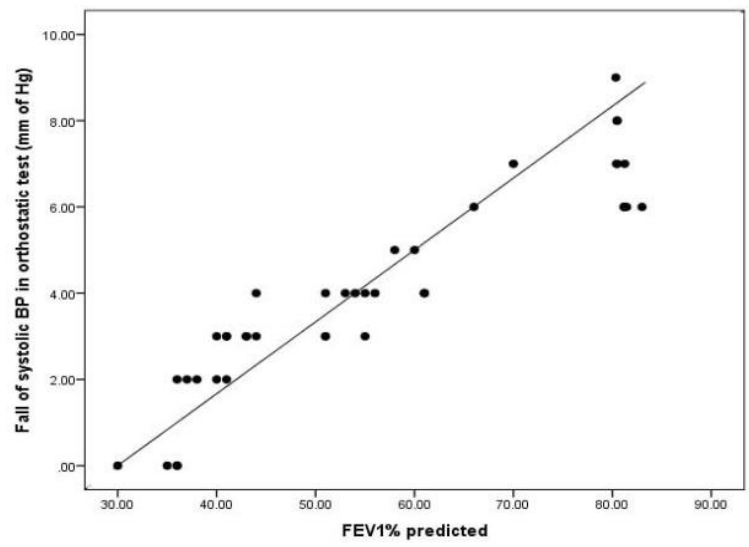

Figure 2: Correlation of fall of systolic BP in orthostatic test with percentage of predicted value of $\mathrm{FEV}_{1}$ in study group $(\mathrm{n}=40)$

\section{Discussion}

In this study, 40 known cases of stable COPD patients with age ranged from 40 to 55 years were included. Age and sex matched 40 healthy subjects were also included for comparison with study group. No statistically significant differences were observed between the groups in respect to age, weight, height and BMI. Age more than 55 years was excluded to avoid the effect of aging on autonomic nervous system.

This study revealed resting pulse rate of COPD patients were significantly higher than that of normal healthy control group. These findings are consistent with other studies. ${ }^{5,15,16-18}$

Resting systolic BP of COPD patients were found significantly higher than that of control group in this study. These findings are compatible with some other investigators. ${ }^{5,17,19,20}$
This study showed diastolic BP of COPD patients was significantly higher than that of control group. Some researchers found similar results. ${ }^{5,19,20} \mathrm{But}$ some other researchers found no significant difference of diastolic BP in between COPD patients and healthy control group. ${ }^{17,21}$

In this study, decline of SBP in response to standing from lying position was found significantly lower in COPD than in the control group. Similar observation was also reported by some investigators. ${ }^{5}$ However, Chabra and Sajal found increased fall of SBP in the orthostatic test. ${ }^{22}$ This opposite result might be due to different age group(mean age 57.96 years). Stewart et al. also found increased fall of SBP during orthostatic test in hypercapnic COPD patients. ${ }^{23}$ This contradictory result might be due to different age group (mean age 66 years), life style and race.

The present study revealed rise of diastolic BP in isometric exercise test in COPD was significantly higher than that of normal control group. These findings are consistent with other researchers. ${ }^{5}$ However, Stewart et al.found no significant difference of rise of diastolic BP after sustained handgrip in between COPD patients and normal control group. ${ }^{23}$ This variation might be due to different age group, life style and race.

This study revealed resting pulse rate, resting SBP, resting DBP and rise of DBP in isometric exercise test were negatively correlated with percentage of predicted value of $\mathrm{FEV}_{1}$ in COPD patients. These relationships were statistically significant. Significant positive correlation was found between decline of SBP in orthostatic test and the percentage of predicted value of $\mathrm{FEV}_{1}$ in COPD patients.

The exact mechanism of sympathetic overactivity in COPD is yet to be known. One of the most important possible mechanism by which cardiovascular sympathetic activity is increased in COPD patients is, hypoxia induced chemoreceptor activation. Some other mechanisms that have been proposed to increase sympathetic activity in patients with COPD include reduced baroreceptor sensitivity, systemic inflammation and oxidative stress. ${ }^{6}$

Hypoxia induced chemoreceptor activation and direct stimulation to RVLM by hypoxia might be the most important factors for this change.

\section{Conclusion}

This study revealed that sympathetic cardiovascular function is overactive in COPD and sympathetic overactivity correlates with the severity of the disease.

\section{Conflict of interest: None}




\section{References}

1. GOLD (Global Initiative for Chronic Obstructive Lung Disease), 2013, 'Global strategy for Diagnosis, Management and Prevention of COPD', accessed at April, 2013 fromwww.goldcopd.org/guideline.

2. Davidson S. Principles \& Practice of Medicine. Reed Elsevier India Private Limited. New Delhi:pp. 673-75, 2014.

3. Ganong WF. Review of Medical Physiology. Tata McGraw Hill Education Private Limited, New Delhi: 2012, pp. 255-66.

4. Guyton AC \& Hall JE. Textbook of Medical Physiology. Saunders, Philadelphia, 2011, pp. 729-40.

5. Aggarwal S, Meena A, Kaur N, Baghhal R \& Sidhu RS. Autonomic Nervous System Changes in Chronic Obstructive Pulmonary Disease (COPD) Patients. Journal of Clinical and Diagnostic Research. 2011; 5:1535-36.

6. Van Gestel AJR, Kohler M \& Christian, FC.2012, 'Sympathetic Overactivity and Cardiovascular Disease in Patients with COPD' viewed on 24 April 2013; accessed at url: discoverymedicine. com/ Arnoldus- J-R-Van Gestel/ 2012 / 12.html.

7. Crofton, J \& Dauglas A. Crofton and Douglas's Respiratory Medicine. Blackwell Science Ltd, UK. 2000; 616-50.

8. Sin DD. Is COPD Really a Cardiovascular Disease? ChestJournal,2009;136:329-30.

9. McGarvey LP, John M, Anderson JA, Zvarich M \& Wise RA. Ascertainment of cause-specific mortality in COPD: operations of the TORCH clinical endpoint committee. Thorax. 2007;62: 411-15.

10. Ewing DJ, Clarke BF. Diagnosis and management of diabetic autonomic neuropathy. British Medical Journal.1982; 285: 916-18.

11. Akter S, Begum N, Ferdousi S, Begum S \& Ali T. Sympathetic Nerve Function Status in Obesity. Journal of Bangladesh Society of Physiologist. 2010; 5: 34-39.

12. Mathias CI and Bannister R. Autonomic failure. A Textbook of Clinical Disorders of The Autonomic Nervous System. $3^{\text {rd }}$ ed. Newyork: Oxford University Press; 1992.
13. Gnanadesigan E, Anand P, Balumahendran K \& Gnangurudasan E. Autonomic Nervous System and Type-2 Diabetes Mellitus. Asian Journal of Biomedical and Pharmaceutical Sciences. 2013; 3:4-9.

14. Hutchison R. Hutchison's Clinical Methods. Elsevier Limited, China: 229-30; 2007.

15. Bartels MN, Jelic S, Ngai P, Basner RC \& DeMeersman RE. High-Frequency Modulation of Heart Rate Variability during Exercise in Patients with COPD. Chest Journal.2003; 123:863-69.

16. Seshadri N, Gildea TR, McCarthy K, Pothier C \& Kavuru MS Association of an Abnormal Exercise Heart Rate Recovery with Pulmonary Function Abnormalities. Chest Journal.2004;125: 1286-91.

17. Sabit R, Bolton CE., Edwards PH, Pettit RJ \& Evans WD 2007, Arterial Stiffness and Osteoporosis in Chronic Obstructive Pulmonary Disease. Am J Respir Crit Care Med.175: 1259-65.

18. Van Gestel AJR, Kohler M, Steier J, Teschler S, Russi EW \& Teschler H. Cardiac autonomic dysfunction and health-related quality of life in patients with chronic obstructive pulmonary disease. Respirology. 2011; 16: 939-46.

19. Mills NL, Miller JJ, Anand A, Robinson SD \& Frazer GA. Increased arterial stiffness in patients with chronic obstructive pulmonary disease: a mechanism for increased cardiovascular risk. Thorax.2007; 63: 306-11.

20. Aidar NA, Silva MAC, Silva CAM Junior, PNF \& Tavares P. ABPM in COPD Patients with Sleep Desaturation. Arq Bras Cardiol.2009; 93: 255-61.

21. Sin DD \& Man SF. Clinical Investigation and Reports-Why are patients with chronic obstructive pulmonary disease at increased Risk of Cardiovascular Diseases? The potential role of systemic inflammation in chronic obstructive pulmonary disease. Circulation. 2003; 107: 1514-19.

22. Chabra SK \& De S. Cardiovascular autonomic neuropathy in chronic obstructive pulmonary disease. Elsevier Respiratory Medicine. 2005; 99: 126-33.

23. Stewart AG, Waterhouse JC \& Howard P. Cardiovascular autonomic nerve function in patients with hypoxaemic chronic obstructive pulmonary disease. Eur Respir J.1991; 4: 1207-14. 